\title{
Correction to: "Relationships Between Salinity and Short-Term Soil Carbon Accumulation Rates from Marsh Types Across a Landscape in the Mississippi River Delta"
}

\author{
Melissa M. Baustian ${ }^{1} \cdot$ Camille L. Stagg $^{2} \cdot$ Carey L. Perry $^{3} \cdot$ Leland C. Moss $^{4} \cdot$ Tim J. B. Carruthers $^{1} \cdot$ Mead Allison $^{5}$ \\ Published online: 29 August 2020 \\ (C) Society of Wetland Scientists 2020
}

Corrigendum to: Wetlands (2017) 37:313-324

https://doi.org/10.1007/s13157-016-0871-3

\begin{abstract}
Salinity alterations through sea-level rise from climate change and coastal restoration strategies will likely change the plant and environmental characteristics in coastal marshes thereby influencing soil carbon accumulation rates. Coastal Louisiana marshes have been historically classified as fresh, intermediate, brackish, or saline based on resident plant community and position along a salinity gradient. Short-term total carbon accumulation rates were assessed by collecting $10-\mathrm{cm}$ deep soil cores at 24 sites located in marshes spanning the salinity gradient. Bulk density, total carbon content, and the short-term accretion rates obtained with feldspar horizon markers were measured to determine total carbon accumulation rates. Despite some significant differences in soil properties among marsh types, the mean total carbon accumulation rates among marsh types were not significantly different (mean \pm std. err. of $382 \pm 55 \mathrm{~g} \mathrm{TC} \mathrm{m}^{-2} \mathrm{yr}^{-1}, \mathrm{n}=15$ ). However, regression
\end{abstract}

The online version of the original article can be found at https://oi.org/ 10.1007/s13157-016-0871-3

Melissa M. Baustian

mbaustian@thewaterinstitute.org

1 The Water Institute of the Gulf, 1110 River Road South, Suite 200, Baton Rouge, LA 70802, USA

2 U.S. Geological Survey, Wetland and Aquatic Research Center, 700 Cajundome Blvd., Lafayette, LA 70506, USA

3 Vernadero Group Incorporated, 3400 S. Carrollton Ave. \#850752, New Orleans, LA 70185, USA

4 Abt Associates, 301 Main Street, Suite 2200, Baton Rouge, LA 70802, USA

5 Department of Earth \& Environmental Sciences, Tulane University, New Orleans, LA 70118, USA analysis indicated that mean annual surface salinity had a significant negative relationship with total carbon accumulation rates. Based on both analyses, the coastal Louisiana total marsh area $(1,433,700 \mathrm{ha})$ accumulates about 5.5 to $7.3 \mathrm{Tg}$

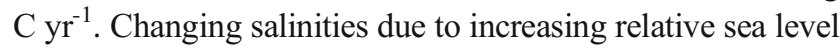
or resulting from restoration activities may alter carbon accumulation rates in the short term and significantly influence the global carbon cycle.

The authors regret that we unknowingly used erroneous bulk density data in Figs. 4 and 6 (panels b,c,e) that affected results in Fig. 7. We carefully examined these data for accuracy following this discovery and successfully corrected the data. Any reference to our January 2017 paper about the bulk density data, carbon density data, short-term carbon accumulation rates, and pool estimates should be disregarded. The results from the analysis with the corrected bulk density data are provided below along with the revised figures (Figs. 4, 6, and 7). The authors would like to apologize for any inconvenience caused.

Correcting the bulk density data changed some of the results (mainly the absolute values) but not the overall trends that were reported in the original manuscript. Our overall conclusions, however, remain essentially unchanged. Our study indicates that soils in coastal Louisiana marshes are storing about $6-8 \%$ of the maximum global carbon estimates and are likely influencing carbon cycling.

\section{Edits to published article:}

\section{Methods}

$\underline{\text { Site Description }}$

A total of 24 marsh sites were selected for this study in the Mississippi and Atchafalaya delta regions of Louisiana within four marsh types. We defined marsh types based on plant community composition and salinity values (sensu Visser et al., 2002). Each marsh type (fresh, intermediate, brackish, 
and saline, Chabreck 1972) was associated with a particular salinity range (Cowardin et al. 1979; Odum 1984). However, because multiple factors influence the distribution of marsh plants, and many species occur over a wide range of salinity conditions, some sites may exist outside of the defined salinity range for a particular wetland type. Six sites each were sampled within four marsh types: fresh, intermediate, brackish, and saline (Odum et al. 1984; Visser et al. 1998) spanning two hydrologic basins, Terrebonne and Barataria (Fig. 1). Dominant vegetation included: Panicum hemitomon and Typha latifolia at fresh marshes, Sagittaria lancifolia and Scheonoplectus americanus at intermediate marsh types, Spartina patens and Scheonoplectus americanus at brackish marsh types, Spartina alterniflora and Juncus romerianus at saline marsh types. The 24 sites, which have been characterized in previous ecological studies (Stagg et al., in revision) encompassed a relatively broad geographical landscape $(\sim$ $65 \mathrm{~km}$ ) (Fig. 1) and were co-located with Coastwide Reference Monitoring Systems (CRMS) stations (http:// lacoast.gov/crms2/home.aspx). Since 2006, continuous hydrological (salinity, temperature, water level) and discrete vegetation, soil, and elevation data have been collected at the CRMS sites (Steyer et al. 2003).

\section{Collection of Soil Cores}

Soil cores were collected at the 24 sites in February 2015 or June/July 2015. The coring location was approximately $25 \mathrm{~m}$ inland from the shoreline at each site and cores were collected to a depth of $100 \mathrm{~cm}$ with a McCaulley or Russian peat corer (inside diameter $=5.1 \mathrm{~cm}$, one-half volume of a full cylinder). Only the top $10 \mathrm{~cm}$ of the core was utilized for the present study. Each core was sectioned into 2-cm depth intervals in the field, placed in whirlpaks ${ }^{\circledR}$, and stored in ice until transported to a laboratory for post-processing and further analysis.

\section{$\underline{\text { Organic Matter Conversion }}$}

Soil samples from each 2-cm increment were freeze-dried to a constant weight to determine $\%$ moisture and dry bulk density and then ground using a mortar and pestle. Loss on ignition methodology was used to determine soil organic matter content and inorganic matter via combustion at $550{ }^{\circ} \mathrm{C}$ for $14 \mathrm{~h}$ (Wilson and Allison 2008). Supplemental soil cores from a previous study (Baustian et al. unpublished data) helped to develop a conversion rate from soil organic matter to total carbon content for soil samples with these region-specific characteristics (Craft et al. 1991; Morris et al. 2016). Supplementary soil cores were collected with a PVC corer (10.16 cm inner diameter, $30 \mathrm{~cm}$ long, sliced at $4 \mathrm{~cm}$ increments) at various CRMS sites in Barataria, Breton, and Atchafalaya basins. These soil samples were simultaneously analyzed for organic matter (via Loss on Ignition, Heiri et al. 2001), total organic carbon, and total carbon according to USEPA methodology of 440 . The total organic carbon $(\%)$ and total carbon (mineral + organic, \%) of the soil layers collected previously in fresh to saline marsh types were significantly correlated to the soil organic matter (\%) (Fig. 2). The soil total organic carbon fraction on average contributed about $97 \%$ of the soil total carbon, therefore these parameters are near identical and both can be used to estimate carbon content. A conversion factor of 0.47 obtained from the regression coefficient of the total carbon vs. soil organic matter was applied to the mean soil organic matter values obtained at the 24 sites in this study (Fig. 1, colored circles) to provide informed estimates of carbon content. This conversion rate is similar to other studies that reported a slope of 0.45 between organic matter and organic carbon $(50 \mathrm{~cm}$ length cores including samples from forested wetlands) in coastal Louisiana (based on $n=1142, \mathrm{r}^{2}=0.93, p<0.001$ ) (Piazza et al. 2011; Steyer et al. 2012) and 0.50 between organic matter and total carbon based on $n=287, \mathrm{r}^{2}=0.98, p<0.01$ ) for tidal marsh soils ( $50 \mathrm{~cm}$ length cores) in Connecticut and New York (Hill and Anisfeld 2015).

\section{$\underline{\text { Accretion Estimates }}$}

To estimate short-term total carbon accumulation rates within each marsh type, accretion estimates were calculated using feldspar marker horizon data previously collected at 16 CRMS sites ( $n=4$ for intermediate, $n=6$ for brackish and $n=$ 6 for saline marsh types). The use of feldspar horizon markers was not recommended in the fresh marsh sites $(n=6)$ and some of the intermediate sites $(n=2)$ because they were considered floating marshes (Folse et al. 2014). The accretion measurements began in 2007 and continued through 2015 (Table 1). At each of the sites, an accretion monitoring plot was established and managed by CRMS program using a white feldspar clay as a marker horizon (Folse et al. 2014). Each plot was then sampled bi-annually for two years and less frequently in subsequent years (Folse et al. 2014). See other literature (Cahoon and Turner 1989; Folse et al. 2014; Bianchette et al. 2015) for more details on the feldspar methodology including limitations and benefits as well as details about downloading accretion data from the Coastal Information Management System (CIMS).

\section{$\underline{\text { Environmental Conditions }}$}

Separate soil cores (inner diameter $=5 \mathrm{~cm}$, length $=15 \mathrm{~cm}$ ) were collected to characterize some of the environmental conditions of the marshes in December 2014. For each core, soils were homogenized, weighed, dried at $60^{\circ} \mathrm{C}$, and re-weighed to determine bulk density and $\%$ moisture. A portion of the dried soil was used to measure electrical conductivity by 
mixing with distilled water (1:1 slurry ratio) and analyzed using a YSI model 30 conductivity meter (Rhoades et al. 1996) organic matter, total carbon, and total nitrogen (Nelson and Sommers 1982), and total phosphorus (Aspila et al. 1976). Elevation was another environmental condition that was measured at various locations per site with a Trimble real-time kinematic (RTK) system via GEOID99. Lastly, available annual surface water salinity data between calendar years of 2000 and 2015 were (http://www.lacoast.gov/chart2/ charting.aspx ? laf $=$ crms\&tab $=2$ ) used to calculate the mean annual salinity at each site.

\section{Total Carbon Accumulation Estimates}

The calculation of total carbon accumulation ( $\mathrm{g}$ TC $\mathrm{m}^{-2} \mathrm{yr}^{-1}$ ) in the top $10 \mathrm{~cm}$ of the soil core was determined by multiplying the carbon density $\left(\mathrm{g} \mathrm{C} \mathrm{cm}^{-3}\right)$ by the accretion rate $\left(\mathrm{cm} \mathrm{yr}^{-1}\right)$ following Bernal and Mitsch $(2008 ; 2012)$ and Bianchi et al. (2013).

Coastwide salinity values were obtained from the Ecohydrology and Wetland Morphology simulation models (Meselhe et al. 2013) through publicly available output underlying the 2012 Louisiana Coastal Master Plan (Coastal Protection and Restoration Authority 2012). The model output consists of a spatial distribution of surface water salinity representing year 2010 with centroids of a $500 \times 500 \mathrm{~m}$ grid size. The salinity model outputs were used in a regression equation (with $n=16$ sites, see Fig. 6e) from this study to estimate the total carbon $\left(\mathrm{g} \mathrm{TC} \mathrm{m}^{-2} \mathrm{yr}^{-1}\right)$ per grid cell and then multiplied by the grid size to get the total mass of carbon

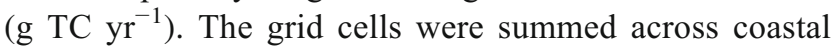
Louisiana marsh area (2013 coastal marsh layer, including floating marshes, delineated by Sasser et al. (2014) to obtain

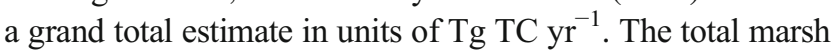
area was estimated at $\sim 1,433,700$ ha.

\section{$\underline{\text { Statistical Analysis }}$}

Statistical analyses and data manipulations were performed in SAS 9.4. Our null hypothesis for all tests was that there was no difference in soil properties (carbon content, bulk density, total carbon density), feldspar accretion rates, and short-term carbon accumulation rates among marsh types and slopes did not differ from zero with $\alpha=0.05$. Slopes of the time-series accretion data as well as the soil properties (\% TC and bulk density were square root transformed), feldspar accretion rates, and short-term accumulation rates versus mean annual salinity were estimated with PROC REG. Extreme outliers in the time-series accretion and mean annual salinity linear regressions were defined and identified if criteria were met by both influence techniques of DFFITS and DBETAS (Belsley et al. 1980; Aguinis et al. 2013) and were removed from further analyses. Approximately 5\% of the feldspar measurements (mean value per plot set per date) were identified as outliers when regressed against time and removed prior to calculating the slopes or accretion rate estimates. Differences among marsh types were evaluated with an analysis of variance (ANOVA) using PROC GLMMIX. Exploratory analysis related to how the environmental conditions (represented as vectors) may vary across (represented as color-coded points) marsh types was conducted with a correlation biplot based on principal component analysis (PCA). A correlation matrix on standardized data and $\alpha$ decomposition of 0.5 for a symmetrical plot with the PROC PRINCOMP statement and biplot macro was used in SAS. Using R software (R Core Team 2013) we conducted an analysis of similarities (ANOSIM) to test statistically whether there was a significant difference in principal components factor scores among the four marsh types.

\section{Results}

\section{$\underline{\text { Soil Properties per Marsh Type }}$}

The mean percent total carbon (TC) in the layers of the top $10 \mathrm{~cm}$ varied among marsh types (Fig. 3). Overall, by pooling the layers per marsh type the mean percent TC was about $32 \pm$ $1 \%, 17 \pm 2 \%, 16 \pm 1 \%$ and $9 \pm 1 \%$ in the fresh, intermediate, brackish and saline marsh types, respectively. A mean of the top four layers per soil core was calculated to estimate the soil properties of the sites including the total carbon accumulation rate.

The mean percent TC ( \pm std. error) and bulk density among the four marsh types significantly differed $(p=0.0001$, Fig. $4 a, b)$. The mean percent TC of the fresh marshes was highest, with intermediate and brackish types similar between each other but significantly higher than the saline marshes (Fig. 4a). Dry soil bulk density in the upper $10 \mathrm{~cm}$ ranged between 0.13 to $0.52 \mathrm{~g} \mathrm{~cm}^{-3}$ among the marsh types and compared to the percent TC the bulk density had a similar significant but opposite trend with increasing salinity of marsh types (Fig. $4 \mathrm{~b})$. The mean total carbon density $\left(\mathrm{g} \mathrm{cm}^{-3}\right)$ was higher in the fresh marsh type $(0.047 \pm 0.002, p=0.002)$ compared to the other three types: intermediate $(0.036 \pm 0.004)$, brackish $(0.034 \pm 0.002)$, and saline $(0.033 \pm 0.002)$ (Fig. $4 \mathrm{c})$.

\section{Accretion Estimates per Marsh Type}

The mean feldspar estimated accretion rates were nearly significantly different among the four marsh types $(p=0.07$, Fig. 4d). The mean feldspar accretion rate was not available for the fresh marsh type while the intermediate marsh type was estimated at $1.71 \pm 0.05 \mathrm{~cm} \mathrm{yr}^{-1}$, brackish at $1.26 \pm$ $0.24 \mathrm{~cm} \mathrm{yr}^{-1}$, and saline marsh type at $0.77 \pm 0.24 \mathrm{~cm} \mathrm{yr}^{-1}$. Accretion rates at brackish and saline sites were highly variable (Fig. 4d). 
TC Accumulation Rates per Marsh Type

The short-term TC accumulation rates ranged between 83 to $787 \mathrm{~g} \mathrm{TC} \mathrm{m}^{-2} \mathrm{yr}^{-1}$ ( $n=16$, Fig. 4e). One intermediate site (CRMS 4045, $274 \mathrm{~g} \mathrm{TC} \mathrm{m}^{-2} \mathrm{yr}^{-1}$ ) was identified and removed as an outlier when regressed on mean annual salinities. The short-term TC accumulation rates for the remaining sites ( $n=$ 15) were then used an ANOVA and these rates were not significantly different across the three marsh types $\left(\mathrm{F}_{2,12}=1.89\right.$, $p=0.19)$. Overall, the grand mean ( \pm std. err.) of the shortterm TC accumulation rates used in the ANOVA $(n=15)$ was $382 \pm 55 \mathrm{~g} \mathrm{TC} \mathrm{m}^{-2} \mathrm{yr}^{-1}$.

\section{Environmental Variables of Marsh Types}

The PCA (Fig. 5) indicated that the first two dimensions accounted for $88 \%$ of the variation of the field samples. From the PCA biplot (Fig. 5), we observed that the field sites tended to cluster into their respective four marsh types irrespective of their basin location with fresh sites on the far right and saline sites on the far left leaving the intermediate and brackish sites intermixed in the middle. The soil properties of organic matter, total carbon, total phosphorus, and total nitrogen had high positive correlation (i.e., small angles between vectors) among each other. For PC1, the compositional dissimilarities among the four wetland types were greater than those within the wetland types, indicating that there was a significant separation of $\mathrm{PC} 1$ parameters among the four wetland types $(\mathrm{R}=0.22, p=0.002)$. High bulk density and electrical conductivity of the soils as well as the mean annual salinity of the surface waters were positively correlated with the saline marsh sites. Elevation seemed to be uncorrelated with the other soil properties. The saline marsh sites had the lowest concentrations of the soil properties of $\% \mathrm{TN}, \% \mathrm{TC}$ and $\%$ TP (i.e., furthest location from the variable).

The soil properties and short-term TC accumulation rates were all significantly related to the mean annual salinities (years 2000 to 2015) of the marsh sites (Fig. 6). The \% total carbon, total carbon density, and feldspar accretion rates all had significant negative relationships with mean annual salinity (Fig. 6a-d). Bulk density was the only soil property that had a positive relationship (Fig. 6b). Mean annual salinity was negatively correlated with the TC accumulation rates (Fig. 6e) and accounted for about $40 \%$ of the variation of the short-term TC accumulation rates $\left(\mathrm{R}^{2}=0.40, p=0.01, n=15\right)$.

\section{Coastwide Estimate of Short-term Carbon Pool}

The total short-term carbon pool of marshes in coastal Louisiana was estimated based on two approaches: the mean annual salinity and short-term TC accumulation regression equation (see Fig. 6e) and the mean value across marsh types, which provides a global context on the amount of marsh soil carbon coastal Louisiana contributes. Based on previously modeled salinity output and our regression equation, the coastal marshes on the central and western region tend to have the highest short-term TC accumulation rates with the eastern area having the lowest and overall the marshes store about 7.3 $\mathrm{Tg} \mathrm{TC} \mathrm{yr}^{-1}$ (Fig. 7). By using the mean value of short-term carbon accumulation rate $\left(382 \pm 55 \mathrm{~g} \mathrm{TC} \mathrm{m}^{-2} \mathrm{yr}^{-1}, n=15\right)$ across the marsh types and the estimated area of marsh in coastal Louisiana $(\sim 1,433,700 \mathrm{ha})$, then these marshes are

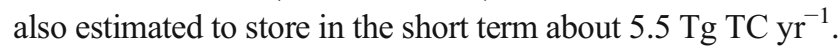

\section{Discussion:}

\section{$\underline{\text { Short-term TC Accumulation Rates }}$}

We detected significant declines in short-term carbon accumulation with increasing salinity when rates were regressed against mean annual salinity of surface waters; however, categorical analysis of short-term carbon accumulation rates showed no significant differences among marsh types, reflecting the high variability of short-term total carbon accumulation within marsh types (fresh, intermediate, brackish and saline). We also observed this pattern with the feldspar accretion rates. Given the regression results, it is clear that salinity, per se, is an important predictor of short-term carbon accumulation rates (Craft 2007). However, because marsh types are not exclusively defined by salinity, analysis of variance among marsh types allows us to identify potential mechanisms associated with marsh type that are not directly related to salinity or may not be explicitly defined in a regression analysis. Therefore, we considered patterns across the salinity gradient as well as among different wetland types. For example, the separation of the marsh sites along the Dimension 1 axis of the PCA helps generalize characteristics about the marsh types. The fresh marshes had higher soil carbon, nitrogen and phosphorus, while the saline marshes had higher bulk density, soil and surface water salinities. As expected, the intermediate and brackish sites had values in between those end members. The fresh marsh sites, with their associated higher soil carbon content, may be associated with higher primary production and perhaps higher short-term carbon accumulation rates. Alternatively, decomposition rates may be slower in the fresher sites compared to the more saline sites, as mentioned previously and supported by William and Rosenheim (2015). Estimates of production and decomposition of organic matter both above and belowground within these four marsh types would help to better explain the net effect that produces these short-term carbon accumulation rates (Neubauer 2008).

Short-term TC accumulation rates from the Gulf region integrated over the top 10-15 $\mathrm{cm}$ of the soil cores were reported by Hansen and Nestlerode (2014) using ${ }^{137} \mathrm{Cs}$ based estimates 
of accretion. They found the brackish marshes dominated by S. patens had short-term TC accumulation rates of $290 \pm$ $170.3 \mathrm{~g} \mathrm{TC} \mathrm{m}^{-2} \mathrm{yr}^{-1}$, salt marshes in Louisiana had $329 \pm$ $217 \mathrm{~g} \mathrm{TC} \mathrm{m}^{-2} \mathrm{yr}^{-1}$ and salt marshes outside of Louisiana as $173 \pm 131 \mathrm{~g} \mathrm{TC} \mathrm{m}^{-2} \mathrm{yr}^{-1}$. They also reported similar mean accretion rates $0.72,0.94$ and $0.57 \mathrm{~cm} \mathrm{yr}^{-1}$ respectively across the three marsh types in their study (Hansen and Nestlerode 2014). Overall, these mean accretion rates and TC accumulation rates are within range of our study, but brackish marshes in the current study had accretion rates $\left(1.26 \mathrm{~cm} \mathrm{yr}^{-1}\right)$ that exceed Hansen and Nestlerode (2014) estimates $\left(0.72 \mathrm{~cm} \mathrm{yr}^{-1}\right)$, and the saline marshes were similar (current study $=0.77 \mathrm{~cm} \mathrm{yr}^{-1}$, Hansen and Nestlerode $(2014)=0.94 \mathrm{~cm} \mathrm{yr}^{-1}$ ).

Short-term total carbon accumulation rates calculated from feldspar methodology from various marsh types along a landscape gradient are not readily available. Our study provides a novel contribution to the growing body of literature on carbon accumulation rates in wetlands by providing insight on how short-term processes (net effect from production, decomposition, bioturbation, etc.) captured in these accumulation rates vary across the coastal landscape, which in turn will likely influence the quality and quantity of carbon being accumulated for the long-term.

Environmental Influences on Short-term TC Accumulation $\underline{\text { Rates }}$

Variation in environmental drivers may help to explain the high variation in TC accumulation rates. Williams and Rosenheim (2015) found, in agreement with our results, that the total organic carbon content (in these soils total carbon percentages are similar) varied significantly among fresh, brackish and saline marshes in Barataria Basin, Louisiana, with fresh marsh soils containing the highest total organic carbon content (\%). They also found from pyrolysis methodology that organic carbon in fresh marsh soils tended to be most stable, or least degradable, among the marsh types and attributed this to a decrease in remineralization due to high water content of the soils and higher recalcitrance of soil organic matter. We also observed a negative relationship between salinity and short-term TC accumulation rates, and $40 \%$ of the variation of the short-term TC accumulation rates was explained by the mean annual salinity from years 2000 to 2015. Craft (2007) and Neubauer (2008) reported negative correlations between vertical accretion rates, which influence short-term TC accumulation rates, and salinity. They suggest that freshwater has positive effects on organic matter production and preservation while saline water stimulated root decomposition resulting in lower rates of organic matter accumulation. Seawater sulfate plays a critical role in regulating decomposition and productivity by enhancing decomposition via sulfate reduction, a process which also generates sulfides that are toxic to plants (Neubauer and Craft 2009).
Coastwide TC Short-term Accumulation

The fresh, intermediate, brackish and saline marshes of coastal Louisiana overall accumulate between 5.5 to $7.3 \mathrm{Tg}$

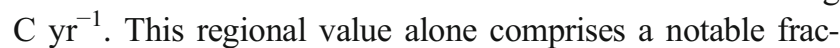
tion $(\sim 6-8 \%)$ of maximum global estimates of carbon accumulation of salt marshes $\left(5-87 \mathrm{Tg} \mathrm{C} \mathrm{yr}^{-1}\right)(\mathrm{Chmura}$ et al. 2003; McLeod et al. 2011) and emphasizes the important role that coastal and deltaic wetlands play in the global carbon cycle. In addition, Mcleod et al. (2011) used an average salt marsh accumulation rate of $218 \pm 24 \mathrm{~g} \mathrm{TC}$ $\mathrm{m}^{-2} \mathrm{yr}^{-1}$ to calculate their global accumulation estimates, which is lower than our mean estimate across the three marsh types (382 $\left.\pm 55 \mathrm{~g} \mathrm{TC} \mathrm{m}^{-2} \mathrm{yr}^{-1}, n=15\right)$. However, it should be noted that the global estimates of areal extent of salt marshes is not well constrained and likely drives the high variability in the global burial estimates (Chmura 2013). Better estimates on areal extent of these marshes would help to refine global carbon budget estimates. These comparisons suggest that, not only do salt marshes play an important role in carbon accumulation and burial, but also, global estimates of carbon accumulation that do not consider salinity changes across coastal landscape gradients may not be accurate. Furthermore, if these marshes transition to more saline marshes due to climate change, or towards fresh marshes due to large scale restoration actions, the shortterm global carbon pool may change. Balancing the greenhouse gas emissions from each of these four marsh types with the short-term carbon accumulation rates may provide a comprehensive understanding of the role of these marshes in overall carbon sequestration (Poffenbarger et al. 2011; Holm et al. 2016; Krauss et al. 2016). For example, fresh marshes may accumulate a large amount of carbon, but they produce methane gas during anaeraboic metabolism, which has a global warming potential that is 25 times greater than carbon dioxide (Whiting and Chanton 2001).

Short-term total carbon accumulation estimates from marsh types that span a salinity gradient illustrate potential implications for ecological responses to sea-level rise and coastal restoration. If surface waters become more saline due to sea-level rise or freshwater limitations, coastal wetlands may transition to a more salt-tolerant plant communities and accumulate less total carbon in their soils (Williams and Rosenheim 2015; Herbert et al. 2015). Conversely, if more freshwater reaches the coast via riverine discharge, restoration management actions such as large river diversions, or increased precipitation events, coastal wetlands may become fresher and accumulate more soil carbon in the short term (Morris et al. 2013). These results also may help guide where along the salinity gradient to place marsh restoration and creation projects to maximize short-term carbon accumulation capacities and potential carbon credits. 

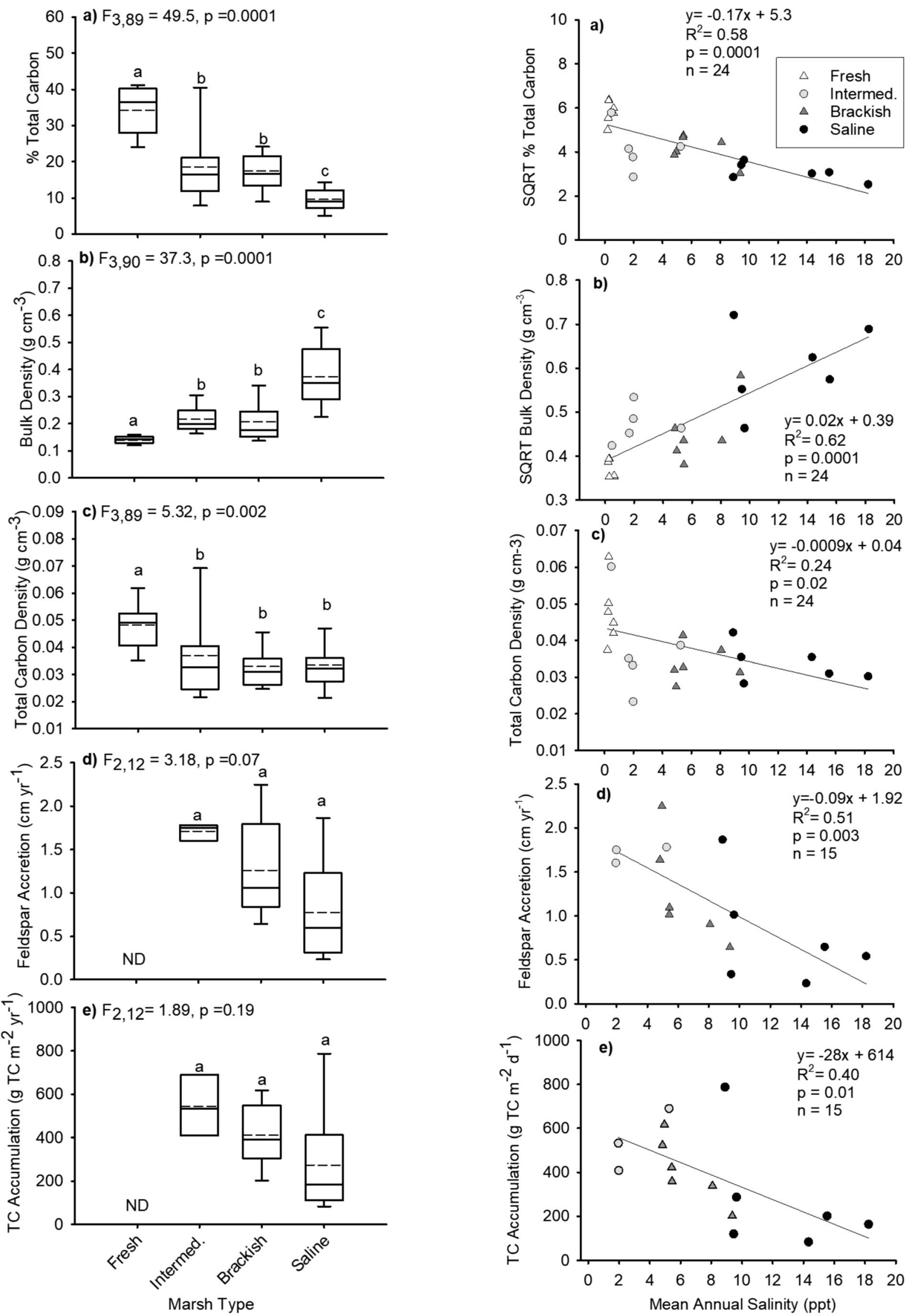


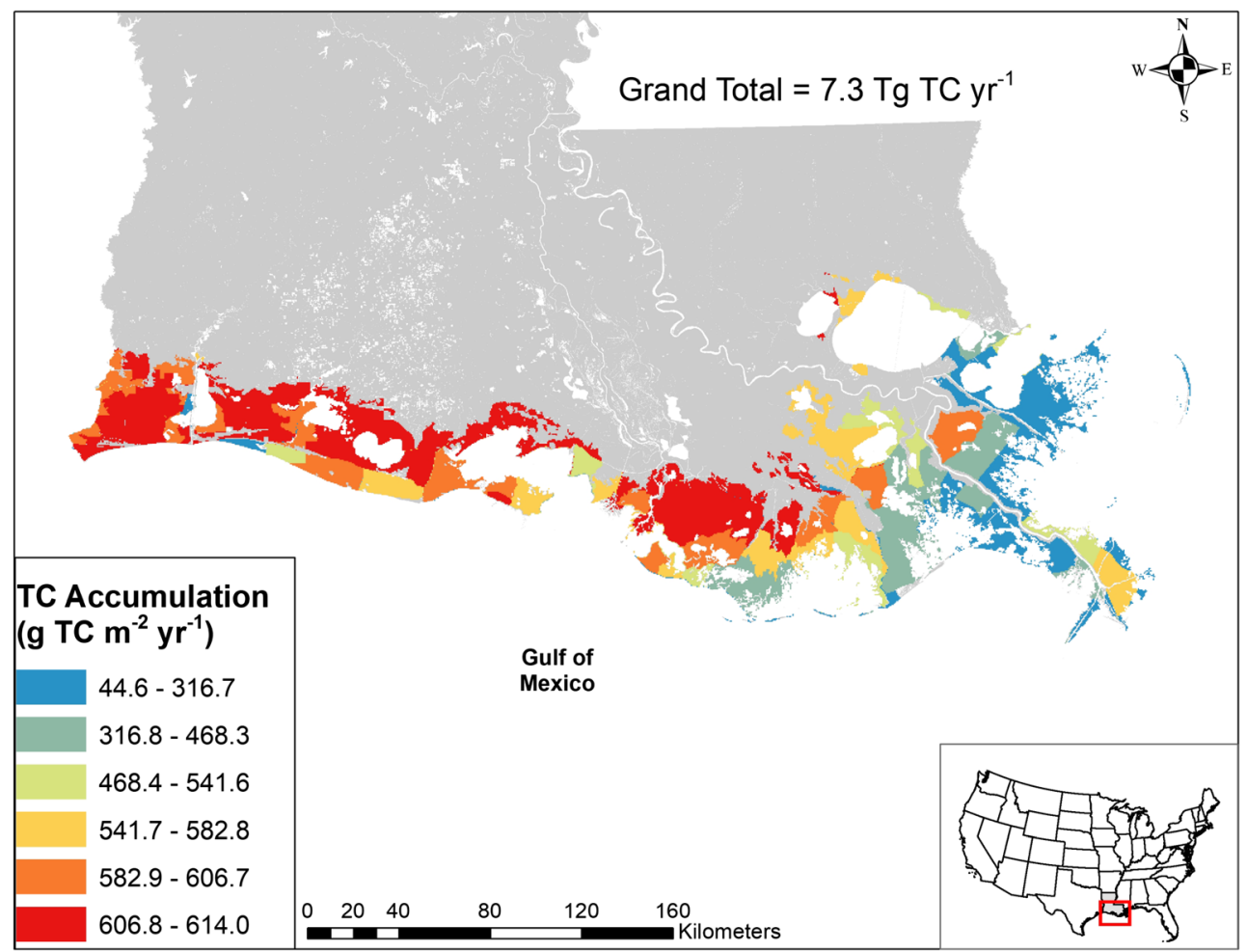

Figures legends:

Fig. 4. Box plots of top $10 \mathrm{~cm}$ soil characteristics of a) total carbon ( $n=22$ fresh, $n=23$ intermediate, $n=24$ brackish, $n=24$ saline), b) bulk density ( $n=23$ fresh, $n=23$ intermediate, $n=24$ brackish, $n=24$ saline), c) total carbon density ( $n=22$ fresh, $n=23$ intermediate, $n=24$ brackish, $n=24$ saline), d) feldspar accretion rates ( $n=0$ fresh, $n=3$ intermediate, $n=6$ brackish and $n=6$ saline) and e) shortterm total carbon accumulation rates $(n=0$ fresh, $n=3$ intermediate, $n=6$ brackish, and $n=6$ saline) representing fourmarsh types, fresh, intermediate, brackish and saline in coastal Louisiana. Different letters indicate significant difference. The box plot dashed line $=$ mean, solid line $=$ median and whiskers above and below the box indicate the 90th and 10 th percentiles. $\mathrm{ND}=$ no data.

Fig. 6. Soil properties (a to c), feldspar accretion rates (d) and short-term total carbon (TC) accumulation rates (e) in relation to mean annual salinity within four marsh types, fresh (open triangle), intermediate (light grey filled circle), brackish (dark grey filled triangle) and saline (black filled circle).

Fig 7. Map of short-term TC accumulation rate estimates in the marshes of coastal Louisiana, USA based on previously modeled spatial salinity output and regression analysis (see Fig. 6e). Grand total of short-term carbon pool for the entire marsh area of coastal Louisiana is listed. Using the mean value of the marsh types suggested a lower grand total of short-term carbon pool of $5.5 \mathrm{Tg} \mathrm{TC} \mathrm{yr}^{-1}$ compared to the regression analysis.

Publisher's Note Springer Nature remains neutral with regard to jurisdictional claims in published maps and institutional affiliations. 